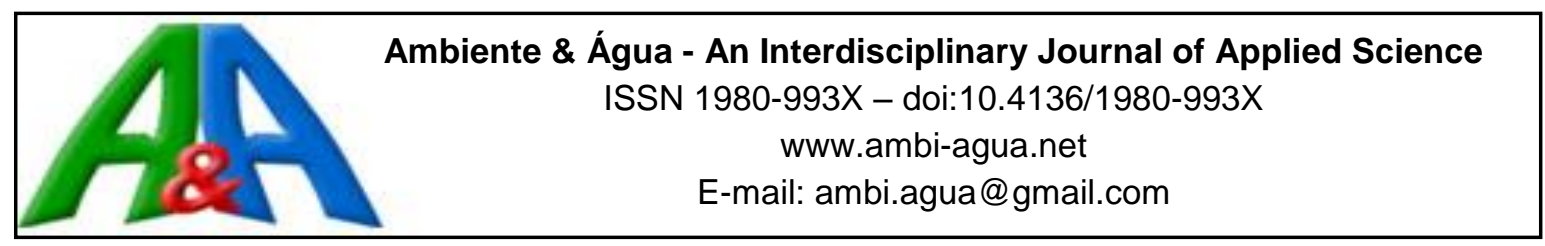

\title{
Qualidade da água do rio Setúbal em Jenipapo de Minas - MG após construção de barragem
}

\author{
doi:10.4136/ambi-agua.1981
}

Received: 08 Aug. 2016; Accepted: 14 Oct. 2017

\author{
Gerson Lucas Alves Martins ${ }^{1 *}$; Alexandre Sylvio Vieira da Costa ${ }^{2}$; \\ Aruana Rocha Barros²; Fernanda Maria Guedes Ramalho \\ ${ }^{1}$ Universidade Federal dos Vales do Jequitinhonha e Mucuri (UFVJM), Teófilo Otoni, MG, Brasil \\ Programa de Pós-Graduação em Tecnologia, Ambiente e Sociedade (PPGTAS) \\ E-mail: gerson_lucas@yahoo.com.br \\ ${ }^{2}$ Universidade Federal dos Vales do Jequitinhonha e Mucuri (UFVJM), Teófilo Otoni, MG, Brasil \\ Instituto de Ciências, Engenharia e Tecnologia (ICET).E-mail: alexandre.costa@ufvjm.edu.br, \\ aruana.barros@ufvjm.edu.br \\ ${ }^{3}$ Universidade Federal de Lavras (UFLA), Lavras, MG, Brasil \\ Programa de Pós-Graduação em Ciência de Tecnologia da Madeira (PPGCTM) \\ E-mail: fernandaguedesrm@hotmail.com \\ *Autor correspondente
}

\section{RESUMO}

A quantidade de recursos hídricos deve ser garantida com a devida qualidade. Neste contexto, o trabalho objetivou caracterizar a qualidade da água do rio Setúbal utilizando o Índice de Qualidade da Água (IQA) e os padrões estabelecidos na Resolução do CONAMA 357/2005, após a construção da barragem de Setúbal, no Município de Jenipapo de Minas MG. Para a caracterização da qualidade da água, seis amostras foram coletadas bimestralmente em dois pontos estratégicos do rio entre junho de 2015 a junho de 2016, sendo analisados os parâmetros: potencial hidrogeniônico $(\mathrm{pH})$, oxigênio dissolvido $(\mathrm{OD})$, temperatura, demanda bioquímica de oxigênio (DBO), nitrato $\left(\mathrm{NO}_{3}{ }^{-}\right)$, fósforo $\left(\mathrm{PO}_{4}{ }^{3-}\right)$, cloreto, turbidez, sólidos totais, ferro total, coliformes totais e Escherichia coli. O IQA foi calculado a partir da metodologia proposta pelo IGAM. De acordo com os resultados, a construção da barragem de Setúbal pode ter contribuído para a alteração de alguns parâmetros físico-químicos e biológicos da água do rio Setúbal. Nos dois pontos de amostragem, a água apresentou um IQA predominantemente de nível médio, porém com algumas variáveis em desconformidade com o enquadramento do rio que é de classe 2 .

Palavras-chave: recursos hídricos, índice de qualidade da água, parâmetros físico-químicos e biológicos.

\section{Water quality of Setúbal river in Jenipapo de Minas - MG after dam construction}

\section{ABSTRACT}

The quality of water resources must be guaranteed. In this context, this study aimed to characterize the water quality of the river Setúbal using the Water Quality Index (WQI) and standards set by CONAMA Resolution 357/2005, after the construction of Setúbal dam in the 
municipality of Jenipapo de Minas - MG. For the characterization of water quality, six samples were collected bimonthly between June 2015 to June 2016 at two strategic river points and the following parameters were analyzed: hydrogen potential $(\mathrm{pH})$, dissolved oxygen (DO), temperature, biochemical demand oxygen (BDO), nitrate $\left(\mathrm{NO}_{3}-\right)$, phosphorus $\left(\mathrm{PO}_{4}{ }^{3-}\right)$, chloride, turbidity, total solids, total iron, total coliforms and Escherichia coli. The WQI was calculated using the methodology proposed by IGAM. The results showed that the construction of Setúbal dam may have influenced changes in some of the physiochemical and biological parameters of Setúbal river's water. The medium WQI level predominated in the two sampling points, but some variables did not reflect the Class2 river category.

Keywords: water resources, water quality index, physical-chemical and biological parameters.

\section{INTRODUÇÃO}

A preocupação com a preservação dos recursos hídricos tem aumentado consideravelmente nas últimas décadas a nível mundial, e isso se deve, dentre os outros motivos, à diminuição da quantidade de água que seja de boa qualidade para as diversas necessidades humanas. Von Sperling (2007) leciona que a qualidade da água é resultante de fenômenos naturais e da atuação do homem, ou seja, do uso e da ocupação do solo. A qualidade das águas deve ser necessariamente conhecida em todos os corpos hídricos pelo motivo de ser um mecanismo capaz de definir estratégias que viabilizem a conservação, a recuperação e o uso racional dos recursos hídricos, reduzindo os conflitos e direcionando as atividades econômicas.

A Agência Nacional de Águas - ANA (2012) destaca que a informação sobre qualidade de água no país ainda é insuficiente ou inexistente em várias bacias. Esta situação ocorre na maioria dos corpos d'água, onde a rede Hidrometeorológica Nacional não abrange padrões de qualidade suficientes e significativos.

A gestão e o monitoramento da qualidade da água são a melhor opção para viabilizar e assegurar esse bem de forma adequada para seus múltiplos usos. Esse monitoramento pode ser realizado por meio de diversos parâmetros que traduzem as suas principais características físicas, químicas e biológicas (Von Sperling, 2007), podendo ainda ser sintetizado pelo Índice de Qualidade da Água (IQA) (ANA, 2012). Uma das técnicas mais utilizadas para determinar o IQA foi desenvolvida pela National Sanitation Foundation Institution (NSF) dos Estados Unidos da América. Fundamentando neste estudo, o Instituto Mineiro de Gestão das Águas (IGAM), dentre outras entidades, modificou o IQA (IGAM, 2012) adequando-o para as condições brasileiras.

A construção de barragens pode estar relacionada a vários problemas associados que podem levar a perda de qualidade da água represada por eutrofização artificial, sanilização, sedimentação, dentre outros (UNEP-IETC, 2003). As barragens se configuram como alternativas essenciais em determinadas regiões devido à necessidade de geração de energia elétrica e o aumento da oferta de água para a agricultura, indústria e consumo doméstico, e por isso tornam-se imprescindíveis para a população (Viana, 2003). De modo geral, essas construções ao longo dos anos vêm atendendo a muitas demandas de populações, amenizando os problemas da falta de água nos períodos de longa estiagem como, por exemplo, em regiões do Vale do Jequitinhonha, Minas Gerais, Brasil. Porém, há impactos negativos que podem ocorrer na região abrangida pelo empreendimento, como alterações no microclima regional, nos sistemas aquáticos naturais, diminuição da concentração de vegetação, alterações na produção, transporte e acúmulo de sedimentos a montante e a jusante, cujos processos de erosão e sedimentação podem causar alterações no leito do rio, redução da qualidade da água com a profundidade, alterações no subsolo devido à flutuação do lençol freático, formação de áreas degradadas e erosivas, e a contaminação de solos pela acumulação de efluentes agrícolas e 
sanitários, tendência à eutrofização e liberação de gás carbônico e metano a partir do fundo do reservatório (Fernandes e Bursztyn, 2008). Esses possíveis impactos devem ser identificados e avaliados, para que sejam adotadas medidas mitigadoras, visando minimizá-los ou evitá-los, de forma que haja maior disponibilidade de recursos hídricos de qualidade (Brasil, 2005a).

Localizado no médio Jequitinhonha, estado de Minas Gerais, o município de Jenipapo de Minas sofre boa parte dos problemas característicos de todo o Vale do Jequitinhonha, principalmente a escassez de recursos hídricos. Dessa forma, a construção da barragem Setúbal, no rio de mesmo nome, foi vista como uma alternativa para maior disponibilidade de recursos hídricos, e, consequentemente, implantação de projetos de cunho de desenvolvimento econômico. Porém, devido aos impactos negativos já abordados, os quais podem ocorrer após a implantação de uma barragem, a água do rio Setúbal, à jusante do barramento, pode não ter sua qualidade adequada para os diversos usos, devendo-se, de forma criteriosa, analisar sua qualidade e, com isso, subsidiar propostas de gestão das águas.

Este trabalho teve como objetivo avaliar a qualidade da água do rio Setúbal, à jusante do barramento de Setúbal, por meio dos padrões estabelecidos pela Resolução do CONAMA 357/2005 e do Índice de Qualidade da Água (IQA) no município de Jenipapo de Minas - MG. Com isso, foi possível verificar se com a implantação da barragem de Setúbal foi garantido o acesso à água de boa qualidade no município.

\section{MATERIAL E MÉTODOS}

\subsection{Caracterização da área de estudo}

O município de Jenipapo de Minas (Figura 1) está localizado no Vale do Jequitinhonha, região nordeste do estado de Minas Gerais, com sede nas coordenadas geográficas

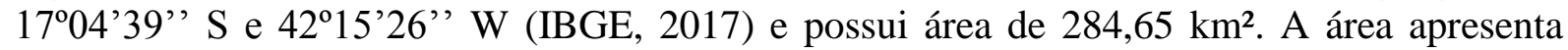
predominantemente um clima tropical de natureza continental, sendo classificado como do tipo Aw, de acordo com a classificação de Köppen. A temperatura média anual varia de 18 e $28^{\circ} \mathrm{C}$, podendo registrar uma máxima anual absoluta de $39^{\circ} \mathrm{C}$. O período entre novembro a janeiro são os mais chuvosos, enquanto a precipitação alcança os seus valores mais baixos entre os meses de maio e setembro, com o mês de julho sendo o mais seco do ano, com precipitação inferior a $10 \mathrm{~mm}$. A tipologia florestal predominante na região é caracterizada como Floresta Estacional Decidual (Mata Seca) a qual é classificada como integrante do Bioma Mata Atlântica, conforme Art. $2^{\circ}$ da Lei Federal $\mathrm{n}^{\mathrm{o}} 11.428$, de 22 de dezembro de 2006 e solos classificados predominantemente como argissolos (IGAM, 2010).

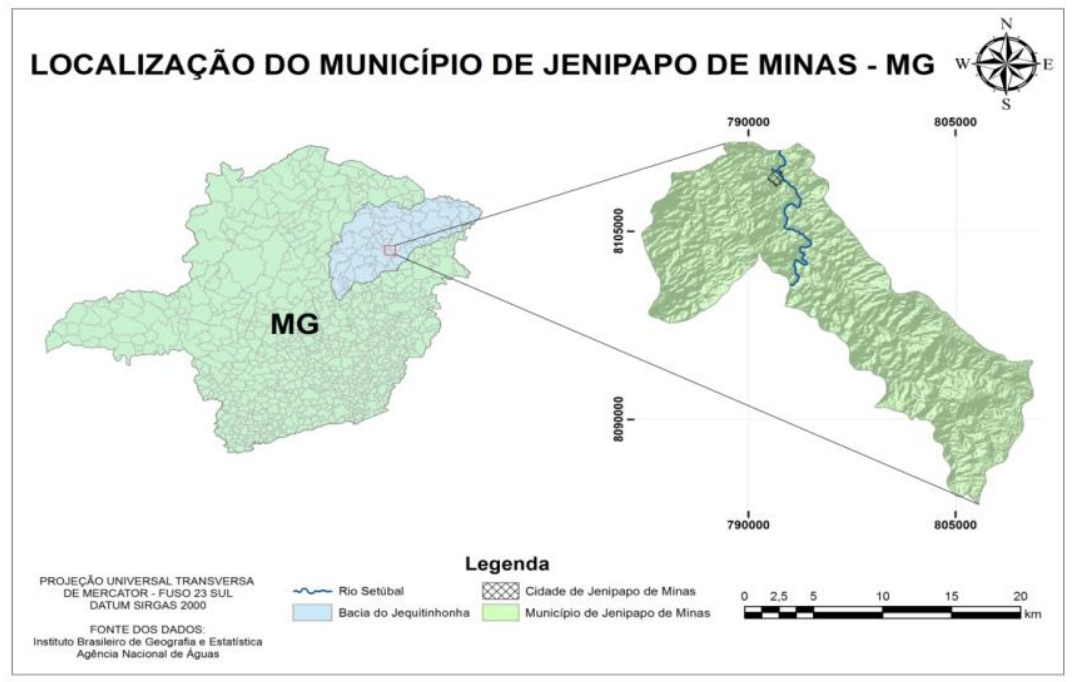

Figura 1. Localização do município de Jenipapo de Minas-MG. 
O curso d'água mais importante de Jenipapo de Minas é o rio Setúbal, o qual é afluente do rio Araçuaí, ambos pertencentes à bacia do rio Jequitinhonha, no nordeste do estado de Minas Gerais (Brasil, 2005b). Os cursos de água ou linhas de drenagem que deságuam no rio Setúbal apresentam caráter intermitente, permanecendo sem água durante o longo período de estiagem. Dessa forma, para que a perenização do rio não fosse comprometida, foi construída a barragem de Setúbal, a qual tem como coordenadas geográficas aproximadas os valores de $17^{\circ} 11^{\prime} 53^{\prime \prime} \mathrm{S}$ e $42^{\circ} 15^{\prime} 17^{\prime \prime}$ W. A barragem de Setúbal foi concluída no ano de 2010, tendo uma área de aproximadamente 980 ha de inundação e capacidade de acumulação no nível d'água máximo de $130.404 .756,94 \mathrm{~m}^{3}$ e nível d'água mínimo de 22.782.245,40 $\mathrm{m}^{3}$. As cotas da soleira do vertedor é $417 \mathrm{~m}$ e da tomada de água é de $397 \mathrm{~m}$, enquanto a descarga regularizada é de $6,5 \mathrm{~m}^{3} \mathrm{~s}^{-1}$. A vazão média de longa duração para o local de implantação da barragem de Setúbal obtida a partir da média das vazões médias anuais é igual a $13,0 \mathrm{~m}^{3} \mathrm{~s}^{-1}$. A vazão mínima de 10 anos de recorrência em 07 dias consecutivos com 10 anos de tempo de retorno $\left(\mathrm{Q}_{7,10}\right)$ verificada para o local de implantação da barragem e calculadas a partir da proposta de regionalização de vazões de Euclydes et al. (2005) foi de 2,62 $\mathrm{m}^{3} \mathrm{~s}^{-1}$, com vazão de pico de $198 \mathrm{~m}^{3} \mathrm{~s}^{-1}$ para o período de retorno de 10 anos. Além de perenizar o rio, a barragem também foi construída no intuito de promover o desenvolvimento socioeconômico no município por meio da maior disponibilidade de recursos hídricos (RURALMINAS, 2005).

\subsection{Amostragem e análise da qualidade da água}

As amostras de água foram coletadas no rio Setúbal em dois pontos de maior representatividade com características diferenciadas. Para seleção dos pontos foi levado em consideração fatores que poderiam influenciar significativamente, de forma direta ou indireta, a qualidade do corpo hídrico, inclusive a presença de descargas, pontuais ou difusas, e as captações, que podem surtir efeito significativo nos resultados.

Rocha et al. (2000) consideram que qualquer tipo de uso do solo em uma bacia hidrográfica interfere no ciclo hidrológico, e, consecutivamente, nos transportes de materiais que interferem na qualidade da água desse manancial. Na Figura 2 é apresentado o mapeamento do uso e cobertura do solo na sub-bacia do rio Setúbal. A Figura ainda destaca a localização da barragem de Setúbal, bem como os pontos de monitoramento de água a sua jusante. Os pontos estão próximos ao perímetro urbano do município de Jenipapo de Minas, às áreas de pastagem e de florestas nativas.

Os pontos amostrados foram respectivamente Ponto 1, acima da descarga de esgoto doméstico da cidade, bem como à jusante da barragem de Setúbal; e Ponto 02, abaixo da descarga de esgoto doméstico (Figura 3). Entre os dois pontos é a parte do rio onde o maior número de produtores rurais capta água para irrigarem suas plantações, bem como onde é feita a captação de água para abastecimento urbano de Jenipapo de Minas. A distância entre o Ponto 1 e a barragem de Setúbal é $11 \mathrm{~km}$. 


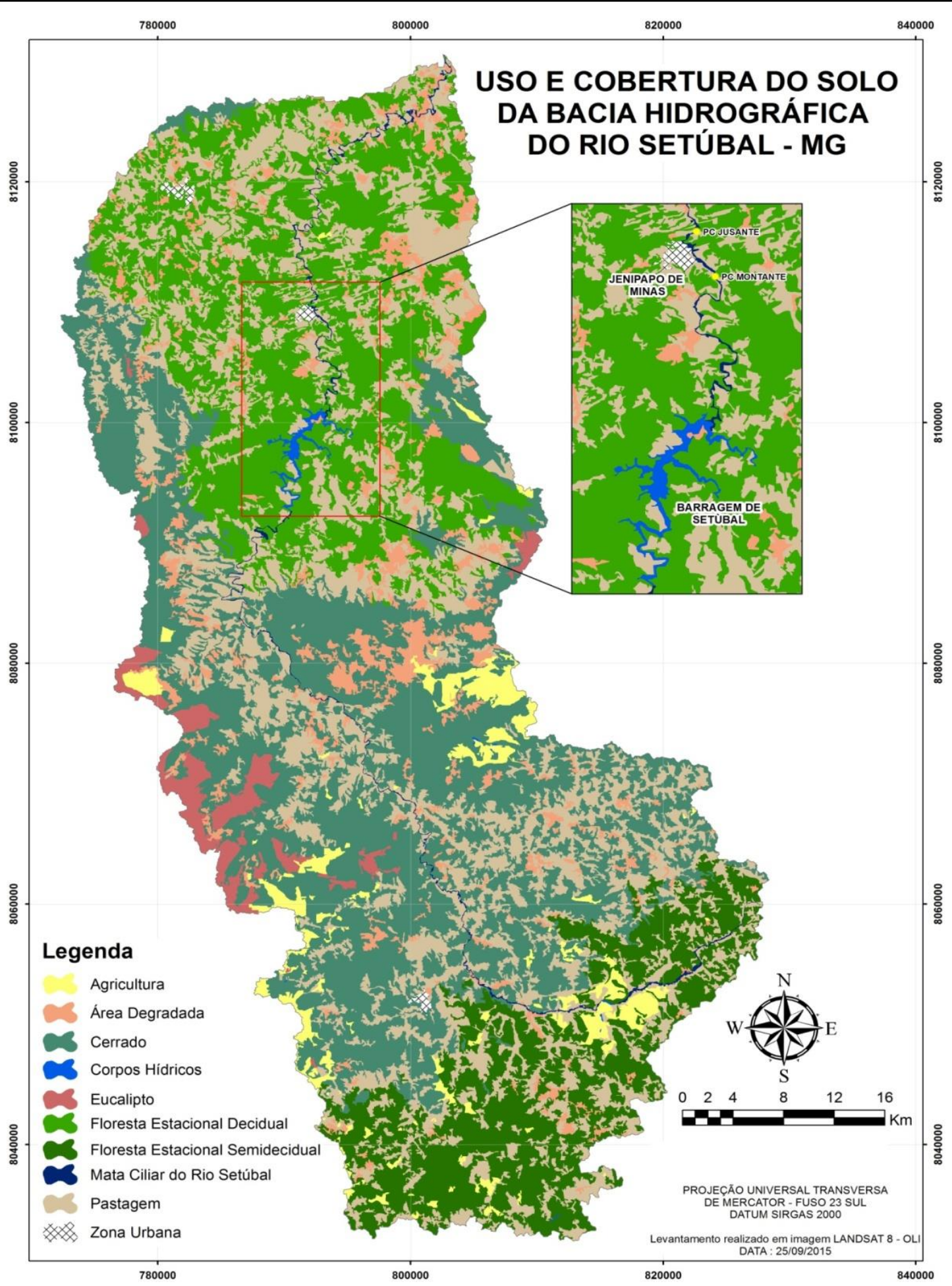

Figura 2. Mapa do uso atual do solo na sub-bacia do rio Setúbal. 

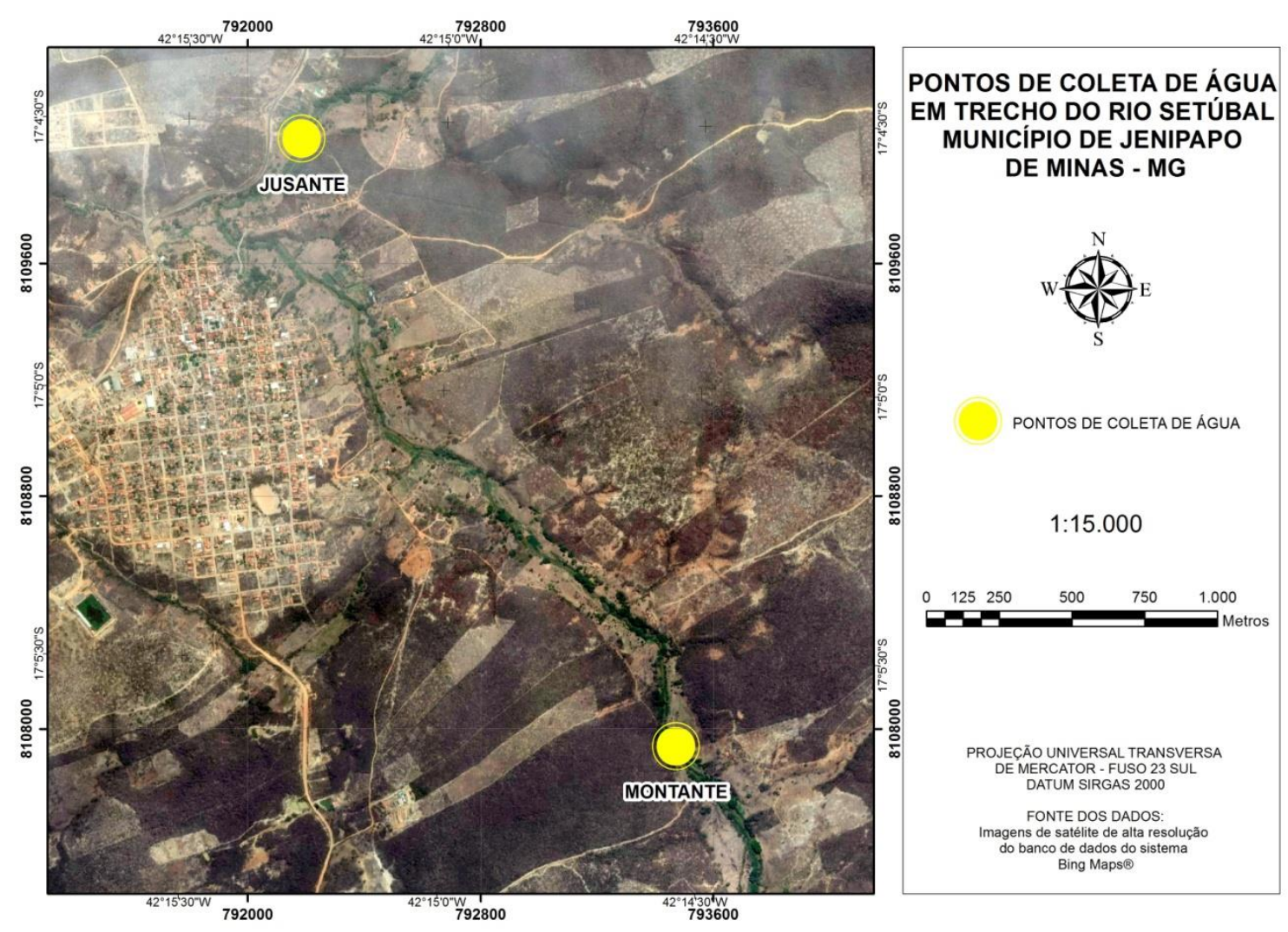

Figura 3. Pontos de coleta de água 1 (montante) e 2 (jusante).

Foram realizadas bimestralmente seis coletas nos pontos supracitados, entre junho de 2015 a junho de 2016. Tal procedimento encontra-se em consonância com a Resolução 357/2005 do CONAMA, que orienta a realização de no mínimo uma amostra bimestral ao longo de um ano para que a caracterização da água em classes seja realizada. As amostras foram retiradas a 20 centímetros da superfície na parte central do leito do rio, dispostas em recipientes específicos e acondicionadas em caixa térmica a fim de manter a temperatura em torno de $4^{\circ} \mathrm{C}$.

A análise dos parâmetros seguiu a metodologia de escolha de reagente, equipamentos, transporte, conservação e análise amostral como descrito no Standard Methods for the Examination of Water and Wastewater-22 ${ }^{\text {nd }}$ edition (APHA et al., 2012), e os valores foram comparados com os da Resolução 357/2005 (CONAMA, 2005) para águas doces de classe 2, uma vez que esse é o enquadramento das águas do rio Setúbal.

Todas as análises foram realizadas no Laboratório Regional Nordeste da COPASA (Companhia de Saneamento de Minas Gerias) em Teófilo Otoni - MG. Os parâmetros avaliados foram: coliformes Totais, Escherichia coli, potencial hidrogeniônico (pH), demanda bioquímica de oxigênio (DBO), temperatura $(\mathrm{T})$, fosfato $\left(\mathrm{PO}_{4}{ }^{3-}\right)$, sólidos totais dissolvidos (STD), oxigênio dissolvido (OD), turbidez $(\mathrm{Tu})$, nitrato $\left(\mathrm{NO}_{3}{ }^{-}\right)$, cloretos $(\mathrm{Cl})$ e ferro total $(\mathrm{Fe}$ total). A seleção desses parâmetros se deve ao fato de que são necessários para o cálculo do Índice de Qualidade da Água e os demais em razão da relevância na caracterização da água do rio Setúbal, bem como na observância do uso e ocupação do solo na região. Metais com maior toxicidade não fazem parte da realidade da sub-bacia do rio Setúbal, de acordo com o Instituto Mineiro de Gestão das Águas (IGAM, 2010).

Aos dados de qualidade da água foi aplicado o Índice de Qualidade de Água (IQA) proposto pelo IGAM (IGAM, 2012), sendo calculado com base nos parâmetros: OD, coliformes fecais, $\mathrm{pH}, \mathrm{DBO}, \mathrm{NO}_{3}{ }^{-}, \mathrm{PO}_{4}{ }^{3-}$, temperatura, turbidez e sólidos totais.

De acordo com Pinto (2009), estes parâmetros foram adotados pela National Sanitation Foundation-NSF (1970), que relaciona nove critérios importantes para caracterização da 
qualidade das águas, com respectivos pesos (w), de acordo com sua relevância. Além disso, cada parâmetro recebe um valor de qualidade (q) que é determinado através de curvas específicas, definidas pela NSF. O IQA foi calculado pelo produtório ponderado das qualidades da água correspondente aos parâmetros conforme a Equação 1:

$I Q A=\prod_{i=1}^{9} q i^{w i}$

Em que: IQA é o índice de qualidade da água, sendo um número de 0 a 100; qi é a qualidade do parâmetro i obtido através da curva média especifica de qualidade; e wi é o peso atribuído ao parâmetro, em função da sua importância na qualidade, entre 0 e 1.A partir do cálculo, foi determinada a qualidade da água, tendo como base a classificação apresentada na Tabela 1.

Tabela 1. Classificação do nível de qualidade conforme valores de IQA.

\begin{tabular}{cc}
\hline Nível de Qualidade & Faixa \\
\hline Excelente & $90<\mathrm{IQA}<100$ \\
Bom & $70<\mathrm{IQA}<90$ \\
Médio & $50<\mathrm{IQA}<70$ \\
Ruim & $25<\mathrm{IQA}<50$ \\
Muito Ruim & $0<\mathrm{IQA}<25$ \\
\hline
\end{tabular}

Fonte: IGAM (2012).

\section{RESULTADOS E DISCUSSÃO}

\subsection{Qualidade da água da sub-bacia hidrográfica do rio Setúbal, segundo a Resolução 357/2005 do CONAMA}

Na Tabela 2, são apresentados os resultados dos parâmetros estudados dos dois pontos amostrados no rio Setúbal, durante um período de um ano.

Nota-se na Tabela 2 que a turbidez e o ferro total foram os parâmetros que mais tiveram os seus valores em desconformidade com a Resolução do CONAMA 357/2005, sendo que suas concentrações estiveram acima do limite para classe 2 em 100\% das amostras do ponto 1 e do ponto 2. Em razão dessas altas concentrações, todas as amostras das duas estações tiveram classificação 4.

Normalmente, turbidez é afetada pelas condições climáticas, podendo indicar elevados processos de erosão. As águas doce de classe 2, de acordo com a resolução do CONAMA $357 / 2005$, devem ter sua turbidez até 100 UNT, sendo que para fins de potabilidade, a Portaria $n^{\circ}$ 518/2004 da Agência Nacional de Vigilância Sanitária, estabelece que a turbidez não ultrapasse 5 UNT. As amostras dos dois pontos de coleta demonstram um índice significativamente elevado de turbidez, já que em nenhuma das amostragens teve-se valor menor que 100 UNT. Independente da estação climática, ou seja, mesmo não existindo chuvas em algumas datas de amostragem, foram extrapolados os níveis de turbidez para classe 2. Além disso, como versa a Resolução do CONAMA 357/2005, águas com valores de turbidez acima de 40 UNT, como os registrados nas amostragens do rio Setúbal, não deverão ser utilizadas na irrigação de hortaliças que são consumidas cruas. Oliveira e Cunha (2014) encontraram durante o período chuvoso os maiores níveis de turbidez, sendo de 13 UNT e 11 UNT, respectivamente, enquanto Damasceno et al. (2015) registraram os maiores índices de turbidez no período de estiagem, sendo de 34,6 UNT. Dessa forma, percebe-se que os índices de turbidez não estão necessariamente associados à sazonalidade climática. 
Tabela 2. Resultados das análises de qualidade da água, para os parâmetros estudados, nas datas de coleta nos Pontos 1 (montante) e Ponto 02 (jusante).

\begin{tabular}{|c|c|c|c|c|c|c|c|c|c|}
\hline & \multirow{3}{*}{ Parâmetros Avaliados } & \multicolumn{6}{|c|}{ Datas de amostragem } & \multirow{3}{*}{$\begin{array}{l}\text { Média } \\
\text { anual }\end{array}$} & \multirow{3}{*}{$\begin{array}{l}\text { Desvio } \\
\text { padrão }\end{array}$} \\
\hline & & \multicolumn{3}{|c|}{2015} & \multicolumn{3}{|c|}{2016} & & \\
\hline & & $09 / 06$ & $10 / 08$ & $28 / 10$ & $09 / 02$ & 28/03 & $01 / 06$ & & \\
\hline \multirow{12}{*}{$\begin{array}{l}\overrightarrow{8} \\
\overrightarrow{0}\end{array}$} & $\mathrm{pH}$ & 7,4 & 7,4 & 7,5 & 7,4 & 7,4 & 7 & 7,35 & $\pm 0,17$ \\
\hline & $\mathrm{OD}\left(\mathrm{mg} \mathrm{L}^{-1}\right)$ & 6,9 & 7,4 & 6,9 & 5,3 & 6,7 & 6,5 & 6,61 & $\pm 0,71$ \\
\hline & $\mathrm{T}\left({ }^{\circ} \mathrm{C}\right)$ & $21^{\circ}$ & $22^{\circ}$ & $21^{\circ}$ & $22^{\circ}$ & $22^{\circ}$ & $21^{\circ}$ & 21,5 & $\pm 0,54$ \\
\hline & $\mathrm{DBO}\left(\mathrm{mg} \mathrm{L}^{-1}\right)$ & 1,1 & 0,87 & 0,36 & 1,1 & 5,8 & 14,1 & 3,88 & $\pm 5,38$ \\
\hline & $\mathrm{NO}_{3}^{-}\left(\mathrm{mg} \mathrm{L}^{-1}\right)$ & 1 & 0,4 & 3,1 & 1,8 & 0,26 & 2,1 & 1,44 & $\pm 1,09$ \\
\hline & $\mathrm{PO}_{4}^{-3}\left(\mathrm{mg} \mathrm{L}^{-1}\right)$ & 0,29 & 0,14 & 0,09 & 0,1 & 0,06 & 0,01 & 0,11 & $\pm 0,09$ \\
\hline & Turbidez (UNT) & 147 & 113 & 102 & 173 & 255 & 260 & 174,83 & $\pm 68,89$ \\
\hline & $\mathrm{S} . \mathrm{T}\left(\mathrm{mg} \mathrm{L}^{-1}\right)$ & 166 & 128 & 128 & 244 & 243 & 260 & 194,83 & $\pm 61,23$ \\
\hline & C.T. (NMP $100 \mathrm{~mL}^{-1}$ ) & 1.300 & 792 & 2.905 & 618 & 961 & 55.600 & $10.363,00$ & $\pm 22177,0$ \\
\hline & E. coli $\left(\mathrm{NMP} 100 \mathrm{~mL}^{-1}\right)$ & 186 & 108 & 199 & 206 & 387 & 201 & 214,5 & $\pm 92,09$ \\
\hline & $\mathrm{Cl}\left(\mathrm{mg} \mathrm{L}^{-1}\right)$ & 5,9 & 5,9 & 5,5 & 5,5 & 7,6 & 5,7 & 6,01 & $\pm 0,79$ \\
\hline & Fe Total $\left(\mathrm{mg} \mathrm{L}^{-1}\right)$ & 9,3 & 7,6 & 6,5 & 10,2 & 14,7 & 15,9 & 10,7 & $\pm 3,80$ \\
\hline \multirow{12}{*}{ 光 } & $\mathrm{Ph}$ & 7,2 & 7,5 & 7,5 & 7,3 & 7,3 & 7,2 & 7,33 & $\pm 0,13$ \\
\hline & $\mathrm{OD}\left(\mathrm{mg} \mathrm{L}^{-1}\right)$ & 7,1 & 7,1 & 6,6 & 5,9 & 6,1 & 6,6 & 6,56 & $\pm 0,49$ \\
\hline & $\mathrm{T}\left({ }^{\circ} \mathrm{C}\right)$ & $21^{\circ}$ & $22^{\circ}$ & $21^{\circ}$ & 22 & $22^{\circ}$ & $21^{\circ}$ & 21,5 & $\pm 0,54$ \\
\hline & $\mathrm{DBO}\left(\mathrm{mg} \mathrm{L}^{-1}\right)$ & 1 & 0,72 & 0,25 & 1,1 & 6,6 & 8,1 & 2,96 & $\pm 3,44$ \\
\hline & $\mathrm{NO}_{3}^{-}\left(\mathrm{mg} \mathrm{L}^{-1}\right)$ & 0,5 & 0,5 & 1,3 & 2,9 & 0,28 & 2,2 & 1,28 & $\pm 1,06$ \\
\hline & $\mathrm{PO}_{4}^{-3}\left(\mathrm{mg} \mathrm{L}^{-1}\right)$ & 0,4 & 0,43 & 0,05 & 0,13 & 0,07 & ND & 0,21 & $\pm 0,18$ \\
\hline & Turbidez (UNT) & 145 & 114 & 101 & 173 & 254 & 262 & 174,66 & $\pm 69,36$ \\
\hline & S.T $\left(\mathrm{mg} \mathrm{L}^{-1}\right)$ & 164 & 148 & 126 & 220 & 212 & 244 & 185,66 & $\pm 46,31$ \\
\hline & C.T. (NMP $100 \mathrm{~mL}^{-1}$ ) & 689 & 2.420 & 10.112 & 6.355 & 2.419 & 63.100 & 14182,5 & $\pm 24205,6$ \\
\hline & E. coli(NMP $\left.100 \mathrm{~mL}^{-1}\right)$ & 238 & 1.733 & 1.120 & 1.986 & 756 & 517 & 1058,33 & $\pm 689,48$ \\
\hline & $\mathrm{Cl}\left(\mathrm{mg} \mathrm{L}^{-1}\right)$ & 7,2 & 7,2 & 4,8 & 6,6 & 9,4 & 6,2 & 6,9 & $\pm 1,51$ \\
\hline & Fe Total $\left(\mathrm{mg} \mathrm{L}^{-1}\right)$ & 9,1 & 7,3 & 6,5 & 10,1 & 13,3 & 15,4 & 10,28 & $\pm 3,46$ \\
\hline
\end{tabular}

$\mathrm{pH}=$ potencial hidrogeniônico, $\mathrm{OD}=$ oxigênio dissolvido, $\mathrm{T}=$ temperatura, $\mathrm{DBO}=$ demanda bioquímica de oxigênio, $\mathrm{NO}_{3}=$ nitrato, $\mathrm{PO} 4=$ fósforo, $\mathrm{ST}=$ sólidos totais, $\mathrm{CT}=$ coliformes totais, E. coli=Escherichia Coli, $\mathrm{CI}=$ cloretos, $\mathrm{Fe}=$ ferro, $\mathrm{ND}=\mathrm{Não}$ detectado.

Os valores de sólidos totais encontram-se dentro dos padrões aceitáveis, como versa a resolução 357/2005 do CONAMA, onde o máximo permitido é de $500 \mathrm{mg} \mathrm{L}^{-1}$ para a classe 2 . Mesmo com esses valores de sólidos totais dentro do permitido pela resolução supracitada, Barboza et al. (2011), em estudo sobre qualidade de água para irrigação, mencionam que valores superiores a 18,63 $\mathrm{mg} \mathrm{L}^{-1}$, como é o caso de $100 \%$ das amostragens dos pontos 1 e 2, gera risco potencial ao sistema de irrigação. Os sais podem fazer parte dos sólidos dissolvidos, o seu excesso na água utilizada na irrigação pode acarretar a salinização do solo, dificultando ou impedindo a absorção de água pelas plantas (Ferreira et al., 2006). Em seus estudos, a Comissão Mundial de Barragens (CMB, 2000) também constatou elevados valores de turbidez e sólidos totais à jusante do barramento de Tucuruí, mesmo nos períodos de estiagem.

As alterações na concentração de ferro em corpos hídricos, segundo Libânio (2010), não apresentam riscos sanitários diretos, porém se encontrado em quantidades elevadas pode ocasionar alterações no sabor da água impossibilitando seu consumo, assim como inconvenientes estéticos por ocasionar manchas em tecidos e em outras superfícies de contato como a precipitação e obstrução de tubulações em sistemas de irrigação. Os valores máximos de ferro permitidos para águas de classe 2, como versa a Resolução do CONAMA 357/2005, é 
de $0,3 \mathrm{mg} \mathrm{L}^{-1}$. Em todas as amostragens dos pontos 1 e 2 das águas do rio Setúbal foram registrados valores acima do permitidos, com médias anuais de 10,7 e 10,28 $\mathrm{mg} \mathrm{L}^{-1}$, respectivamente, e, portanto, representa alto potencial de danos ao sistema de irrigação (Barboza et al., 2011). Nota-se que os valores de ferro nos dois pontos não tiveram diferenças significativas, podendo inferir que as altas concentrações desse componente são advindas à montante dos pontos amostrais, sendo possivelmente acumulado na barragem de Setúbal, já que a decomposição de material no lago pode liberar compostos orgânicos complexos como o ferro. Sobre isso, Pimentel (2004) explica que em alguns reservatórios pode ocorrer a estratificação térmica vertical em determinadas épocas do ano; onde a diferença de temperatura entre as camadas superficial e profunda do reservatório e, consequentemente, a diferença de densidade entre essas camadas, pode comprometer a qualidade da água do reservatório, como, por exemplo, aumentando as concentrações de ferro e outros componentes. Os valores de concentração de ferro nos corpos d'água também podem estar relacionados aos níveis baixos de vazão, vez que em rios com baixa vazão há uma maior propensão em concentrar certos componentes devido à pouca movimentação das águas, dificultando a dispersão e, principalmente no período seco, devido a altas temperaturas ambientais que provocam maior evaporação da água (Oliveira et al., 2010).

Os valores de fósforo estiveram em desconformidade em 33,33\% das amostras do ponto 1 e em $50 \%$ do ponto 2 . Sendo que no ponto 2 as concentrações desse elemento foram mais críticas nas duas primeiras amostras, contribuindo para que a estação obtivesse classificação 4 . Ao serem registrados elevados valores de fósforo, a qualidade da água sofre um decréscimo significativamente. Valores máximos de $\mathrm{PO}_{4}{ }^{3-}$ permitidos pela Resolução $\mathrm{N}^{\circ} 357 / 2005$ do CONAMA para corpos d'água de classe 2 é de $0,1 \mathrm{mg} \mathrm{L}^{-1} \mathrm{em}$ ambiente lótico, como é o caso do rio Setúbal. Os valores de fósforo foram superiores ao permitido em $33 \%$ das amostragens do ponto 1 e $50 \%$ das amostras do ponto 2; sendo que a maior quantidade registrada foi de 0,43 $\mathrm{mg} \mathrm{L}^{-1}$, no ponto 2, no período de estiagem. Pinto et al. (2009) e Damasceno et al. (2015), em pesquisas semelhantes, registraram maiores valores de fósforo nos períodos chuvosos e associaram isso a processos naturais, da dissociação dos sedimentos em suspensão e da lixiviação do solo pelas águas das chuvas, ou seja, fonte difusa. O mesmo não aconteceu com as amostras de água do rio Setúbal, vez que os maiores valores de $\mathrm{PO}_{4}{ }^{3-}$ foram registrados no período de estiagem, e, por isso, infere-se que as principais fontes de fósforo presente no rio Setúbal são pontuais, como, por exemplo, a emissão de efluentes, sem o devido tratamento, provenientes da cidade de Jenipapo de Minas. No entanto, é possível também que o barramento de Setúbal, à montante dos dois pontos de amostragem, contenha esse nutriente acumulado e liberado no rio junto com a água. Sobre isso, a CMB (2000) atesta que em reservatórios pode haver a liberação de compostos químicos, como, por exemplo, o fósforo; porém, a tendência é que haja uma estabilização após a decomposição da floresta inundada, aumentando o nível de qualidade da água, sendo que esse tempo está relacionado à quantidade de vegetação e outros materiais que foram imersos no reservatório.

A DBO também corroborou para que os limites de classe 2 fossem violados em 33,33\% das amostragens das duas estações. De maneira mais crítica, este parâmetro obteve o maior valor na última amostragem do ponto 1 , contribuindo na inserção dessa estação em classe 4 . No entanto, nas quatro primeiras amostras os valores de DBO nos dois pontos de coleta do rio foram menores ou iguais a $1,1 \mathrm{mg} \mathrm{L}^{-1}$, totalizando $66,66 \%$ das amostragens, permitindo que este parâmetro estivesse dentro do limite de enquadramento do rio Setúbal que é de classe 2 $\left(<5 \mathrm{mg} \mathrm{L}^{-1}\right)$ de acordo com a Resolução 357/2005 do CONAMA. A DBO funciona como indicador na qualidade da água, quanto maior a quantidade de efluentes orgânicos, maior será a demanda por oxigênio, comprometendo, assim, a qualidade da água. Os valores acima do indicado, e obtidos nas últimas leituras, sugerem que há substâncias biodegradáveis e matéria orgânica presentes na água. Estudando sobre impactos físicos de barragens, Pimentel (2004)

\section{IPABH}


constatou que os níveis de DBO, à jusante de rios, são alterados após a formação do reservatório, decorrente da presença de matéria orgânica, que por sua vez existe quando não há uma limpeza eficiente da área inundada. Dessa forma, os níveis de DBO, ora baixos, ora elevados, podem estar também relacionados ao reservatório de Setúbal, bem como os variantes níveis de vazão a sua jusante.

Análises de bactérias do grupo coliformes, principalmente coliformes totais e Escherichia coli, são feitas no intuito de avaliar a qualidade bacteriológica da água (Scherer et al., 2016). A garantia do consumo de água potável livre de micro-organismos patogênicos prejudiciais à saúde se configura como um método eficiente de prevenção das doenças causadas pela água (Silva e Araújo, 2003). A concentração de coliformes foi outro parâmetro que apresentou desconformidade, sendo que no ponto 2 estas estiveram em maior desconformidade com os limites de classe 2 , onde $50 \%$ das amostras tiveram valores de coliformes totais e E. coli acima do permitido para esta classe, e, portanto, tiveram classificação 3, especificamente nessas amostragens. No ponto 1, apenas a última amostragem obteve concentrações de coliformes totais acima do limite para águas de classe 2 e $100 \%$ dentro do limite para E. coli. Oliveira et al. (2014) também registraram elevadores valores de coliformes no rio Jari, região da Amazônia brasileira, mesmo em áreas sem fontes de poluição explícitas, associando as concentrações de coliformes às características biológicas dos solos e presença de florestas, mas sem identificar se as fontes são exclusivamente de origem natural ou antropogênica. Esses valores de coliformes totais e de $E$. Coli podem ser relacionados à descarga de esgotos domésticos, à decomposição de material orgânico (como vegetação alagada para construção da barragem de Setúbal), visto que as Citrobacter, Enterobacter e Klebsiella (coliformes totais), são gêneros ocorrentes no solo e na vegetação, não sendo, portanto, de origem exclusivamente fecal (Silva et al., 2011). Além disso, em razão da barragem de Setúbal ser um empreendimento recente, a existência de fossas negras, chiqueiros e cemitérios no local do reservatório podem ter influenciado no aumento do número de coliformes $e$ E. Coli.

Os valores de nitrato, $\mathrm{pH}$ e $\mathrm{OD}$, cloreto e temperatura estiveram dentro dos limites de classe 2 em 100\% das amostras dos dois pontos. Os valores de $\mathrm{pH}$ nos dois pontos de amostragem do rio Setúbal tiveram uma variação pouco significativa, oscilando entre 7,0 a 7,5. A vida aquática depende do $\mathrm{pH}$, sendo que a Resolução ${ }^{\circ}$ 357/2005 do CONAMA versa que os níveis de acidez para águas de Classe 2 devem estar entre 6,0 e 9,0, de modo que, em ambos os pontos de coleta, os valores encontram-se dentro dos padrões aceitáveis pela normatização ambiental, o que pode caracterizar, por exemplo, que a emissão de efluentes no rio Setúbal não tem sido significativa a ponto de causar variações expressivas do $\mathrm{pH}$ da água. Mesmo os valores de $\mathrm{pH}$ se apresentarem dentro dos limites aceitáveis, Scherer et al. (2016) chamam a atenção para quando os valores de $\mathrm{pH}$ se encontrarem entre 6,9 e 7,4, pois pode ocorrer a formação de bicarbonatos, o que torna as águas de irrigação alcalinas.

As concentrações de OD em todas as amostras obtidas dos dois pontos de amostragem foram superiores a $5 \mathrm{mg} \mathrm{L}^{-1}$, valor mínimo para vida aquática, caracterizando baixo efeito da poluição das águas decorrentes de despejos orgânicos. As temperaturas em todas as amostras e pontos oscilaram entre $21^{\circ}$ e $22^{\circ}$, as quais não são altas o suficiente para acelerar as atividades biológicas da vida aquática. Os valores registrados de temperatura podem estar associados ao fato de que as coletas foram feitas nos inícios das manhãs, o que pode ter contribuído também para que não houvesse grandes oscilações sazonais. A existência da barragem de Setúbal também pode ter influenciado nas temperaturas em razão de uma possível estratificação térmica, onde ocorre o esfriamento do fundo do reservatório em relação à superfície (Pimentel, 2004). Portanto, quando isso acontece, a água liberada do fundo do reservatório apresenta temperaturas mais baixas. 
O nitrato é a principal forma de nitrogênio associada à contaminação da água pelas atividades agropecuárias (Resende, 2002). Os valores de nitrato $\left(\mathrm{NO}_{3}{ }^{-}\right)$nos dois pontos de amostragem foram considerados baixos, de acordo com a legislação vigente, tendo concentração mínima de $0,40 \mathrm{mg} \mathrm{L}^{-1}$ e máxima de $3,1 \mathrm{mg} \mathrm{L}^{-1}$, e não variaram significativamente ao longo das amostragens. Assim, independentemente da sazonalidade, não foram detectadas perturbações em relação ao componente nitrato. Um dos fatores responsáveis por isso pode estar relacionado à ausência de indicativos de contaminação significativa por meio das atividades antropogênicas na sub-bacia do rio Setúbal, como, por exemplo, o uso de fertilizantes sintéticos na agricultura.

Von Sperling (2007) leciona que os níveis de cloreto na água podem ter sua origem natural, resultante da dissolução de sais; enquanto que sua origem antropogênica está relacionada a despejos industriais ou domésticos, além de água proveniente de irrigação, pois este componente também está presente em fertilizantes e defensivos agrícolas. Os valores de cloretos $(\mathrm{Cl})$ nos dois pontos de amostragem se apresentaram quase que insignificantes se comparado com o valor estabelecido pela Resolução 357/2005 do CONAMA que é de no máximo $250 \mathrm{mg} \mathrm{L}^{-1}$ de cloreto para águas de classe 2, demonstrando que as fontes poluidoras do rio Setúbal não apresentam níveis elevados desse componente.

\section{2. Índice de Qualidade da Água (IQA) do rio Setúbal}

O IQA calculado para a sub-bacia hidrográfica do rio Setúbal, nos dois pontos de amostragem, encontra-se na Tabela 3.

Tabela 3. Índice de Qualidade da Água nos pontos de amostragem na sub-bacia hidrográfica do rio Setúbal, durante o período de monitoramento, e suas respectivas classificações, segundo o IGAM.

\begin{tabular}{ccccc}
\hline \multirow{2}{*}{$\begin{array}{c}\text { Data de } \\
\text { Amostragem }\end{array}$} & \multicolumn{4}{c}{ IQA-(IGAM) } \\
\cline { 2 - 5 } & PONTO 01 & Classificação & PONTO 02 & Classificação \\
\hline $09 / 06 / 15$ & 55,70 & Médio & 54,90 & Médio \\
$10 / 08 / 15$ & 61,10 & Médio & 50,90 & Médio \\
$28 / 10 / 15$ & 55,50 & Médio & 60,10 & Médio \\
$09 / 02 / 16$ & 53,20 & Médio & 47,20 & Ruim \\
$28 / 03 / 16$ & 54,90 & Médio & 51,90 & Médio \\
$01 / 06 / 16$ & 48,80 & Ruim & 50,30 & Médio \\
\hline Média anual & 54,86 & Médio & 52,55 & Médio \\
Desvio Padrão & $\pm 3,98$ & & $\pm 4,45$ & \\
\hline
\end{tabular}

Nota-se pela Tabela 3 que em todas as datas de amostragem os valores de IQA para o ponto 1 ficaram classificados em um nível de qualidade médio, exceto na última amostragem que teve uma classificação ruim. A variação do IQA nesse ponto de amostragem foi entre 48,80 a 61,10, sendo a média anual de 54,86 $\pm 3,98$. O parâmetro que mais influenciou negativamente nesse ponto foi a turbidez, a qual representa $8 \%$ no cálculo do IQA, e teve altos valores em todas as amostras. Os valores de E. coli, fósforo, nitrato e DBO também tiveram contribuições significativas para que o IQA do ponto 1 não alcançasse melhor classificação. O elevado valor de DBO na última amostragem desse ponto teve grande influência para que o IQA nessa data tivesse classificação ruim. No ponto 2 , os valores de IQA tiveram uma variação entre 47,20 a 60,10 , com uma média anual de 52,55 $\pm 4,45$. Nota-se que o IQA médio predominou nesse ponto, sendo que apenas na quarta amostragem a classificação foi ruim. Assim, como no ponto 1, a turbidez influenciou negativamente no IQA de todas as amostragens. As concentrações de fósforo, nitrato e E. coli também tiveram grande contribuição para que o IQA não alcançasse 
melhor nível de classificação. Comparando as concentrações de E. coli entre os dois pontos de amostragem, percebe-se que no ponto 2 estas foram significativamente maiores, fator este que

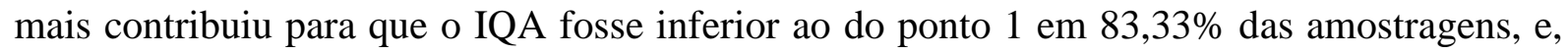
portanto, obteve uma média anual também inferior.

Estando o ponto 2 à jusante do perímetro urbano de Jenipapo de Minas, é possível inferir que o esgoto da cidade lançado no rio Setúbal contribuiu para a maior concentração de coliformes e, consequentemente, afetou o IQA, deixando a qualidade da água inferior em relação ao ponto 1 , à montante da cidade. O IQA das amostras do rio Setúbal não tiveram significativas diferenças anuais, e nem mesmo elevados índices pluviométricos com escoamento superficial, e, portanto, esses não são fatores que influenciaram nos níveis de IQA. Pereira et al. (2013) também não registraram grandes diferenças nos valores de IQA do rio Juma entre as estações climáticas, sendo obtida classificação boa tanto no período de seca, quanto no chuvoso. Já Damasceno et al. (2015) registraram um IQA de 76,70 no período de estiagem e de 80,93 no chuvoso, em que a estação chuvosa apresentou melhor índice de qualidade. Os autores explicaram que isso acontece em razão da diluição dos contaminadores no período de chuva. Dessa forma, possivelmente, maiores vazões provenientes da barragem de Setúbal podem ocasionar na diluição de alguns contaminantes e, consequentemente, elevar o IQA do rio, principalmente no ponto 2 , onde há descarga de efluentes sem tratamento.

O reservatório de Setúbal exerce, possivelmente, influência nos níveis de classificação do IQA dos pontos amostrais. Braga et al. (2005) instruem que a qualidade da água em um reservatório depende da altura das tomadas e da época do ano, ou seja, pode ter qualidade pior durante o período de estratificação térmica em função da posição. Para os autores, esse tipo de episódio se configura como uma das maiores preocupações quanto às alterações ambientais provocadas por barragens, já que a má qualidade da água à jusante da barragem pode atingir uma extensão de rio bastante significativa.

As concentrações de ferro foram elevadas em todas as amostragens dos dois pontos amostrais, no entanto, este elemento não é considerado na elaboração do IQA. Sobre isso Buzelli e Cunha-Santino (2013) mencionam que há necessidade de analisar uma série de outras variáveis que não compõem o IQA para se obter resultados mais detalhados sobre a qualidade da água.

\section{CONCLUSÃO}

O IQA do rio Setúbal nos pontos de maior captação para uso humano no município de Jenipapo de Minas teve registros de níveis predominantemente médios. A construção da barragem de Setúbal pode ter contribuído para a alteração de alguns parâmetros físico-químicos e biológicos da água do rio Setúbal, e, consequentemente, obtendo um IQA de nível médio. Os elevados valores de turbidez e ferro total se mostraram em desacordo com os limites para águas de classe 2, conforme a Resolução 357/2005 do CONAMA, em todas as amostras nos dois pontos de amostragem, fazendo com que todas as amostras tivessem classificação 4. O esgoto lançado do perímetro urbano de Jenipapo de Minas contribuiu para a alteração de alguns parâmetros no ponto 2, principalmente na maior concentração de coliformes. Dessa forma, foi possível perceber que a qualidade da água, à jusante do barramento de Setúbal, encontra-se comprometida para o consumo humano, pois os valores de alguns parâmetros estão em desacordo com o que é preconizado pela Resolução 357/2005 do CONAMA. Por isso, o tratamento de efluentes antes de serem lançados no rio e gestão do reservatório de Setúbal se configuram como alternativas para melhorar a qualidade da água. 


\section{REFERÊNCIAS}

AGÊNCIA NACIONAL DAS ÁGUAS - ANA (Brasil). Panorama da qualidade das águas superficiais no Brasil: 2012. Brasília, 2012. 264 p.

AMERICAN PUBLIC HEALTH ASSOCIATION - APHA; AMERICANWATER WORKS ASSOCIATION - (AWWA); WATER ENVIRONMENT FEDERATION - (WEF). Standard Methods for examination of water and wastewater. $22^{\text {nd }}$ ed. Washington, 2012. 1360 p.

BARBOZA, G. C.; HERNANDEZ, F. B. T.; FRANCO, R. A. M. Análise dos riscos a sistemas de irrigação causados pela qualidade da água do Córrego Coqueiro - SP. Revista Brasileira de Agricultura Irrigada, v. 5, n. 1, p. 24-36, 2011.

BRASIL. Ministério da Integração Nacional. Secretaria de Infraestrutura Hídrica. Unidade de Gerenciamento do Proágua/Semiárido. Diretrizes ambientais para projeto e construção de barragens e operação de reservatórios. Brasília: Bárbara Bela Editora Gráfica e Papelaria Ltda., 2005a.

BRASIL. Ministério de Minas e Energia. Projeto cadastro de fontes de abastecimento por água subterrânea. Belo Horizonte, 2005b. 13p.

BRAGA, B.; HESPANHOL, I.; CONEJO, J. G. L.; MIERZWA, J. C.; BARROS, M. T. L.; SPENCER, M. et al. Introdução à engenharia ambiental. 2. ed. São Paulo: Pearson Prentice Hall, 2005. 313p.

BUZELLI, G. M.; CUNHA-SANTINO, M. B. Análise e diagnóstico da qualidade da água e estado trófico do reservatório de Barra Bonita (SP). Revista Ambiente \& Água, v. 8, n. 1, p. 186-205, 2013. http://dx.doi.org/10.4136/ambi-agua.930

COMISSÃO MUNDIAL DE BARRAGENS (CMB). Estudo de caso brasileiro, Usina Hidrelétrica de Tucuruí (Brasil), Relatório de Final. Cape Town, 2000.

CONSELHO NACIONAL DO MEIO AMBIENTE - CONAMA. Resolução n 357, de 17 de março de 2005. Dispõe sobre a classificação dos corpos de água e diretrizes ambientais para o seu enquadramento, bem como estabelece as condições e padrões de lançamento de efluentes, e dá outras providências. Diário Oficial [da] União, Brasília, n. 53, p. 5863, 18 mar. 2005.

DAMASCENO, M. C. S. D.; RIBEIRO, H. M. C; TAKIYAMA, L. R.; PAULA, M. T. Avaliação sazonal da qualidade das águas superficiais do Rio Amazonas na orla da cidade de Macapá, Amapá, Brasil. Revista Ambiente \& Água, v. 10, n. 3, 2015. http://dx.doi.org/10.4136/ambi-agua.1606

EUCLYDES, H. P.; FERREIRA, P. A.; FARIA FILHO, R. F. R. Atlas digital das águas de Minas. Viçosa: UFV, RURALMINAS, IGAM, 2005. 78 p.

FERREIRA, P. A.; MOURA, R. F. de; SANTOS, D. B. dos; FONTES, P C. R.; MELO, R. F. Efeitos da lixiviação e salinidade da água sobre um solo salinizado cultivado com beterraba. Revista Brasileira de Engenharia Agrícola e Ambiental, v. 10, n. 3, p. 570 578, 2006. http://dx.doi.org/10.1590/S1415-43662006000300006 
FERNANDES, C. T. C.; BURSZTYN, M. A. A. Usos múltiplos das águas de reservatórios de grandes hidrelétricas: perspectivas e contradições ao desenvolvimento regional sustentável. In: ENCONTRO NACIONAL DA ASSOCIAÇÃO NACIONAL DE PÓSGRADUAÇÃO E PESQUISA EM AMBIENTE E SOCIEDADE, 4., 2008, Brasília. Anais... São Paulo: ANPPAS, 2008.

INSTITUTO BRASILEIRO DE GEOGRAFIA E ESTATÍSTICA. Jenipapo de Minas. Disponível em: https://goo.gl/DHrz5N. Acesso: 30 out. 2017.

INSTITUTO MINEIRO DE GESTÃO DAS ÁGUAS. Plano diretor de recursos hídricos da bacia hidrográfica do Rio Araçuaí. Relatório Final. Volume I. UPGRH JQ2. Maceió: GAMA Engenharia de Recursos Hídricos Ltda, 2010.

INSTITUTO MINEIRO DE GESTÃO DAS ÁGUAS. Monitoramento da qualidade das águas superficiais de Minas Gerais em 2012: resumo executivo. Belo Horizonte: IGAM. 2012. 47p.

LIBÂNIO, M. Fundamentos de qualidade e tratamento de água. 3. ed. Campinas: Átomos, 2010.

OLIVEIRA, B. S. S. de; CUNHA, A. C. da. Correlação entre qualidade da água e variabilidade da precipitação no sul do Estado do Amapá. Revista Ambiente \& Água, v. 9, n. 2, 2014. http://dx.doi.org/10.4136/ambi-agua.1287

OLIVEIRA, C. N. de; CAMPOS,V. P.; MEDEIROS, Y. D. P. Avaliação e identificação de parâmetros importantes para a qualidade de corpos d'água no semiárido baiano. Estudo de caso: bacia hidrográfica do rio Salitre. Química Nova, v. 33, n. 5, p. 1059-1066, 2010. http://dx.doi.org/10.1590/S0100-40422010000500010

PEREIRA, A. R.; SANTOS, A. de A.; SILVA, W. T. P.; FROZZI, J. C.; PEIXOTO, K. L. G.. Avaliação da qualidade da água superficial na área de influência de um lixão. Revista Ambiente \& Água, v.8, n. 3, 2013. http://dx.doi.org/10.4136/ambi-agua.1160

PINTO, D. B. F.; SILVA, A. M. da; MELLO, C. R. de; COELHO, G. Qualidade da água do ribeirão Lavrinha na região Alto do Rio Grande - MG, Brasil. Revista Ciência e Agrotecnologia, v. 33, n. 4, p. 1145-1152, 2009. http://dx.doi.org/10.1590/S141370542009000400028

RESENDE, A. V. Agricultura e qualidade da água: contaminação da água por nitrato. Brasília: Embrapa Cerrados, 2002. 29p.

ROCHA, O.; PIRES, J. S. R.; SANTOS, J. E. dos. A bacia hidrográfica como unidade de estudo e planejamento. In: ESPINDOLA, E. L. G.; SILVA, J. dos S. V. da; MARINELLI, C. E.; ABDON, M. de M. (Org.). A bacia hidrográfica do rio Monjolinho: uma abordagem ecossistêmica e a visão interdisciplinar São Paulo: RIMA, 2000. p.1-16.

RURALMINAS. Estudo de Impacto Ambiental-EIA- e Relatório de Controle AmbientalRCA- da barragem de Setúbal. Minas Gerais: Funarbe, 2005. 136 p. 
SCHERER, K.; GRANADA, C. E.; STULP, S.; SPEROTTO, R. A. Avaliação bacteriológica e físico-química de águas de irrigação, solo e alface (Lactuca sativa L.). Revista Ambiente \& Água, v. 11, n. 3, 2016. http://dx.doi.org/10.4136/ambi-agua.1829

SILVA, R. C. A.; ARAÚJO, T. M. Qualidade da água do manancial subterrâneo em áreas urbanas de Feira de Santana (BA). Ciência \& Saúde Coletiva, v. 8, n. 4, p. 1019-1028, 2003. http://dx.doi.org/10.1590/S1413-81232003000400023

SILVA, Í. N.; FONTES, L. DE O.; TAVELLA, L. B.; OLIVEIRA; J. O. de; OLIVEIRA, A. C. de. Qualidade de água na irrigação. ACSA - Agropecuária Científica no Semi-Árido, v. 7, n. 3, p. 01-15, 2011.

UNITED NATIONS ENVIRONMENT PROGRAMME; INTERNATIONAL ENVIRONMENTAL TECHNOLOGY CENTRE. Planning and management of lakes and reservoirs: an integrated approach to eutrophication. Washington, D.C., 2003. $67 \mathrm{p}$.

VIANA, R. M. Grandes barragens, impactos e reparações: um estudo de caso sobre a barragem de Itá. 2003. Dissertação (Mestrado em Planejamento Urbano e Regional) Instituto de Pesquisa e Planejamento Urbano e Regional, Universidade Federal do Rio de Janeiro, Rio de Janeiro, 2003.

VON SPERLING, M. Estudos e modelagem da qualidade da água de rios. Belo Horizonte: UFMG, 2007. 588 p. 